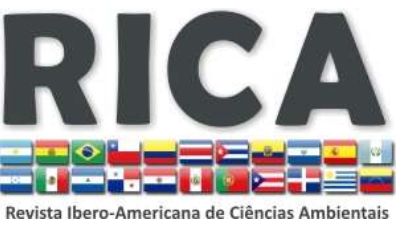

Journals Homepage:

www.sustenere.co/journals

\section{QUALIDADE DA ÁGUA CONSUMIDA PELOS MORADORES DO SEMIÁRIDO PARAIBANO APÓS DESSALINIZAÇÃO}

\section{RESUMO}

Os moradores das regiões Semiáridas do Brasil são vítimas da seca e pobreza devido aos baixos índices pluviométricos existentes nessas localidades, obrigandoos a buscar fontes alternativas de água para sobrevivência a exemplo da água de poço. Devido ao embasamento de rochas cristalinas nestes aquíferos subterrâneos a água captada é sempre composta por grandes quantidades de sais dissolvidos, tornando-a imprópria para consumo humano. Águas com essas características, muitas vezes, são tratadas por meio de dessalinização através de sistemas de membranas de osmose inversa. Esse trabalho teve como objetivo avaliar a qualidade da água produzida pelo dessalinizador da Comunidade de Uruçu, em termos de quantidades de sais. A tecnologia utilizada foi a Osmose Inversa que se mostrou eficaz no tratamento, pois, a água do poço possuía cerca de $1.911,19 \mathrm{mg} / \mathrm{L}$ de sais dissolvido e após o processo de purificação, reduziu para $76,75 \mathrm{mg} / \mathrm{L}$. Esse resultado, obtido através da análise da água, permitiu a caracterização físicoquímica e possíveis comparações com os valores máximos permissíveis estipulados pela Portaria 2914/11 do Ministério da Saúde no Brasil. Com isso, existe a contribuição para a melhoria de vida destes moradores, gera novas atitudes e posteriormente novos conceitos para melhoria da qualidade de vida de pequenas comunidades isoladas que vivem na pobreza e escassez de água potável.

PALAVRAS-CHAVES: Semiárido; Água; Dessalinização; Uruçu.

\section{QUALITY OF WATER CONSUMED BY RESIDENTS OF SEMIARID PARAIBA AFTER DESALINATION}

\section{ABSTRACT}

The residents of the semiarid regions of Brazil are victims of drought and poverty due to low rainfall in these existing locations, forcing them to seek alternative sources of water for survival such as well water. Due to the crystalline basement rocks in these aquifers, the water abstracted is always composed of large amounts of dissolved salts, making it unfit for human consumption. Water with these characteristics is often treated by desalinating using a reverse osmosis membrane system. This study aimed to assess the quality of water produced by desalination of Community Uruçu in terms of the amounts of salt. The technology used was reverse osmosis which proved effective in the treatment, therefore, the well water had about $1911.19 \mathrm{mg} / \mathrm{L}$ of dissolved salts and after the purification process, it was reduced to $76.75 \mathrm{mg} / \mathrm{L}$. This result, obtained through the analysis of water, allowed the physicochemical characterization and possible comparisons with the maximum permissible values stipulated by Decree 2914/11 of the Ministry of Health in Brazil. With this, there is a contribution to the improvement of the life of residents, which generates new attitudes and new concepts to further improve the quality of life of small isolated communities living in poverty and scarcity of drinking water.

KEYWORDS: Semiarid; Water Desalination; Uruçu.
Revista Ibero-Americana de

Ciências Ambientais, Aquidabã, v.6, n.1, Dez 2014, Jan, Fev, Mar, Abr, Mai 2015.

ISSN 2179-6858

\section{SECTION: Articles} TOPIC: Recursos Hídricos

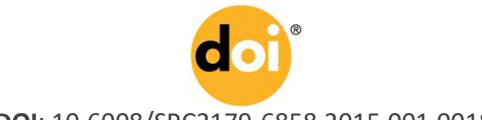

DOI: 10.6008/SPC2179-6858.2015.001.0018

Rodrigo Vieira Alves

Universidade Federal de Campina Grande, Brasil http://lattes.cnpq.br/2943935093134069 rodrigocgnet@gmail.com

Maniza Sofia Monteiro Fernandes Universidade Federal de Campina Grande, Brasil http://lattes.cnpq.br/0782679173169516 maniza-f@hotmail.com

Sonáli Amaral Lima

Faculdade Mauricio de Nassau, Brasil http://lattes.cnpq.br/1409249976949294 sonalial@hotmail.com

Tereziana Silva da Costa

Universidade Federal de Campina Grande, Brasil http://lattes.cnpq.br/7211256067736786 tereziana_sc@hotmail.com

Kepler Borges França

Universidade Federal de Campina Grande, Brasil http://lattes.cnpq.br/3620576114544758 kepler12345@gmail.com

Received: 23/09/2014

Approved: 09/04/2015

Reviewed anonymously in the process of blind peer.

Referencing this:

ALVES, R. V.; FERNANDES, M. S. M.; LIMA, S. A.; COSTA, T. S.; FRANÇA, K. B.. Qualidade da água consumida pelos moradores do semiárido paraibano após dessalinização. Revista Ibero-Americana de Ciências Ambientais, Aquidabã, v.6, n.1, p.222-245, 2015. DOI: http://dx.doi.org/10.6008/SPC2179- 


\title{
INTRODUÇÃO
}

A água é um dos constituintes inorgânicos em maior quantidade no homem, mais de $60 \%$ de sua massa é constituída por água. VON (2005, p.17) afirma em seus textos que:

\begin{abstract}
A água é fundamental para a manutenção da vida, razão pela qual é importante saber como ela se distribui no nosso planeta, os 1,36×1018 m3 de água existentes na Terra distribuem-se da seguinte maneira: água do mar $97 \%$, geleiras $2,2 \%$ e água doce $0,8 \%$, sendo esta última $97 \%$ de água subterrânea e $3 \%$ de água superficial.
\end{abstract}

A qualidade da água é resultante de fenômenos naturais e da atuação do homem. De maneira geral, pode-se dizer que a qualidade de uma determinada água é função das condições naturais, assim, o estudo da qualidade da água é fundamental, tanto para se estabelecer os meios para que se satisfaça determinado uso da água. Com relação às condições climáticas o Brasil é considerado o país com a região semiárida mais populosa do mundo, atualmente a população é estimada em 21 milhões de habitantes. Na região do agreste Paraibano predomina o clima Semiárido, caracterizando-se por altas temperaturas, elevadas taxas de evaporação e baixos níveis de precipitação, que favorece a escassez de água nesta região (IBGE, 2010).

O problema da seca no Semiárido brasileiro é mais um problema social do que natural, visto ser um fenômeno conhecido e a sua ocorrência, previsível. A partir deste conhecimento prévio, torna-se imprescindível o desenvolvimento de ações sustentáveis através de políticas públicas que impeçam esse fenômeno natural, tornar-se um flagelo, que perdura desde o período colonial (LIRA et al., 2012). Outro problema enfrentado pelos moradores do clima Semiárido é que, mesmo contendo uma grande quantidade de recursos hídricos subterrâneos, esta água contém alta concentração de sais, o que a torna imprópria para consumo. A ingestão excessiva dos sais presentes na água causa doenças e até a morte de pessoas e animais. O Semiárido também é uma região de seca em decorrência da falta de chuvas.

Segundo Silveira e França (2009) a solução empregada para ter o acesso à água nestas regiões é a exploração de águas subterrâneas por meio de poços. Evidentemente não é suficiente ter acesso à água, é necessário que tenha um controle de qualidade por meio de avaliação da necessidade de um eventual tratamento da mesma, com a finalidade de evitar doenças veiculadas pelo simples consumo da água. Com esse problema que surgiu a dessalinização de água através de processos com membranas, como uma alternativa viável para amenizar a problemática da seca, visando a produção de água de boa qualidade para o consumo humano, apresentando resultados bastante satisfatórios à alimentação e saúde pública.

No Brasil, o emprego da dessalinização de água ainda é pouco divulgado, embora no Nordeste seja aplicado o processo de osmose reversa para dessalinização de águas salobras oriundas de poços para o abastecimento de pequenas comunidades (SOUZA, 2006). De acordo com Queiroz et al. (2013) atualmente em decorrência da degradação dos recursos hídricos e a dificuldade de manter a água potável por meio das tecnologias de tratamento convencional, a 
utilização dos processos de separação por membranas passa a ser a opção de tratamento para a produção de água potável.

A tecnologia de separação por membranas envolve a utilização de membranas sintéticas, porosas ou semipermeáveis, orgânicas ou inorgânicas e em configuração adequada, para separar de um fluido de partículas sólidas de pequeno diâmetro, bactérias, vírus, moléculas orgânicas, compostos iônicos de baixo peso molecular e até gases. Na microfiltração (MF), ultrafiltração (UF) e osmose inversa (OI), a pressão hidráulica é utilizada para promover a separação entre a água e os contaminantes e é a água que atravessa a membrana. Já no processo de eletrodiálise, a separação é obtida por uma diferença de potencial elétrico aplicado entre as membranas e neste caso são os contaminantes que atravessam a membrana, (HABERT et al., 2006).

Anadão (2010) afirma que a osmose inversa é um processo de separação líquido-líquido, que emprega uma membrana densa semipermeável altamente permeável à água e altamente impermeável a microrganismos, coloides e sais dissolvidos. Com a aplicação de uma pressão maior que a osmótica, o solvente passa pela membrana, a qual age como barreira de fluxo aos solutos, possibilitando a separação do solvente e dos solutos. A necessidade de água potável é um fato cada vez mais preocupante. Pequenas comunidades ou sítios localizados no semiárido Brasileiro, muitas vezes, não possuem acesso à água de boa qualidade. Em muitas dessas localidades, são perfurados poços artesianos com a esperança de se ter acesso aos aquíferos. No entanto, devido às formações cristalinas do solo da região Nordeste, inúmeros poços são abandonados por conta das elevadas concentrações de sais encontradas na água. Águas com essas características, muitas vezes, são tratadas por meio de dessalinização através de sistemas de membranas de osmose inversa. Com o auxílio de programas ou de projetos de desenvolvimento, algumas comunidades têm sido beneficiadas pela instalação de sistemas de dessalinização, para a produção e distribuição de água potável. O presente trabalho tem como objetivo avaliar a qualidade da água produzida por dois dessalinizadores que abastecem duas localidades do Estado da Paraíba no Brasil.

\section{MATERIAIS E MÉTODOS}

\section{Local da Pesquisa}

A localidade de estudo fica situada na zona rural do município São João do Cariri, Figura 1. De acordo com o Instituto Brasileiro de Geografia e Estatística (IBGE) no ano de 2010 teve a população de 4.344 habitantes, Figura 2. 


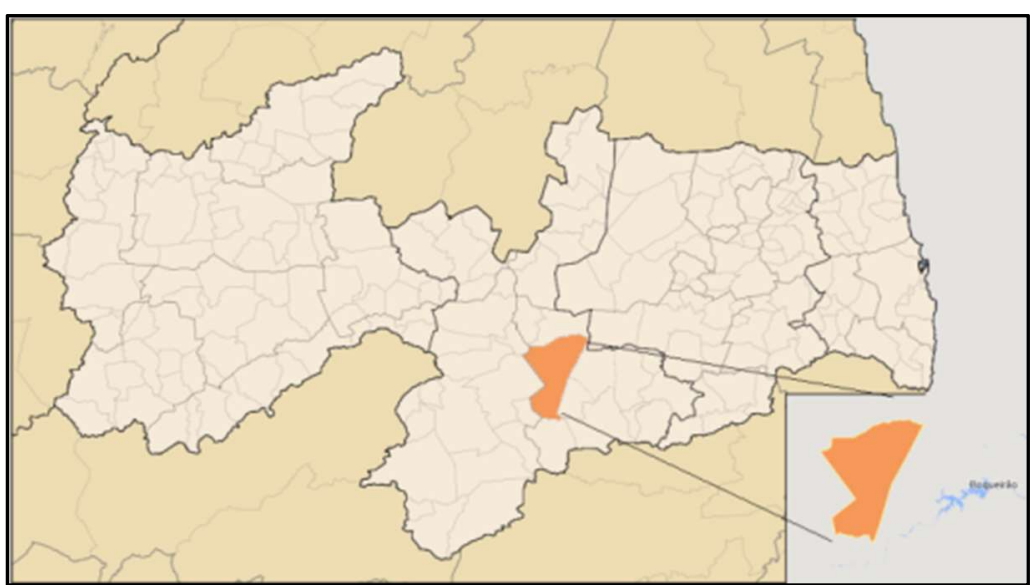

Figura 1: Mapa com a localização da sede da Comunidade Uruçu.

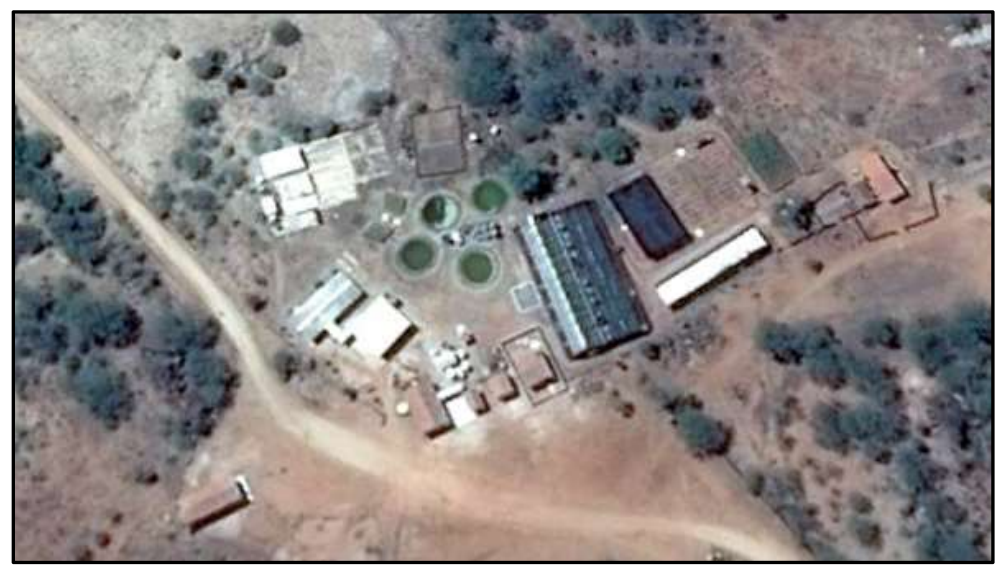

Figura 2: Mapa com a localização da região urbana de São João do Cariri.

Ambas as localidades pertencem à mesorregião da Borborema e a microrregião do Cariri Oriental, geograficamente, a sede comunitária está na latitude $7^{\circ} 28^{\prime} 33^{\prime \prime}$ ao sul e longitude de 36 31'51" a oeste e fazendo fronteira com: Serra Branca, Gurjão, Parari, Santo André (PB), Cabaceiras, São Domingos do Cariri, Barra de São Miguel, Caraúbas e Coxixola. A localidade de Uruçu conta com aproximadamente 80 famílias que vivem em pequenas propriedades. $A$ área que compõe Uruçu é formada por três localidades distintas, nomeadas de Várzea Grande, Uruçu de Cima e Uruçu (LIRA, 2012).

A região está incluída na área geográfica de abrangência do semiárido brasileiro. Esta delimitação tem como critérios o índice pluviométrico, o índice de aridez e o risco de seca. As chuvas são, portanto irregulares e esparsas e temperaturas médias na ordem dos $30^{\circ}$. Com menos de $234 \mathrm{~mm}$ de chuva durante o ano todo, as precipitações ocorrem apenas durante três meses, dando vazão a estiagens que duram até dez meses nos períodos mais secos, conferindo a Cabaceiras o título de município onde menos chove no país, dados do Instituto Nacional de Meteorologia, 2005. O dessalinizador da Comunidade Uruçu faz parte do projeto 'Água: Fonte de Alimento e Renda - Uma alternativa sustentável para o Semiárido' implantado pela Petrobras através do Programa Petrobras Ambiental e parceria com o LABDES (Laboratório de Referência em Dessalinização/UFCG). 


\section{Coletas das Amostras}

Para a conclusão deste trabalho, foram feitas visitas de campo a localidade do dessalinizador, Figura 3, durante os meses: maio, junho e julho de 2013. No local, foram coletadas amostras de três pontos do dessalinizador, uma amostra da água permeada, uma do rejeito e uma do poço em cada visita realizada. Realizaram-se as análises físico-químicas no LABDES Laboratório de Referência em Dessalinização da Universidade Federal de Campina Grande sendo analisados os seguintes parâmetros: $\mathrm{pH}$, turbidez, cor, ferro, amônia, dureza, sódio, cloreto e sólidos totais dissolvidos (STD). Os quais foram determinados de acordo com a metodologia descrita no APHA (1998).

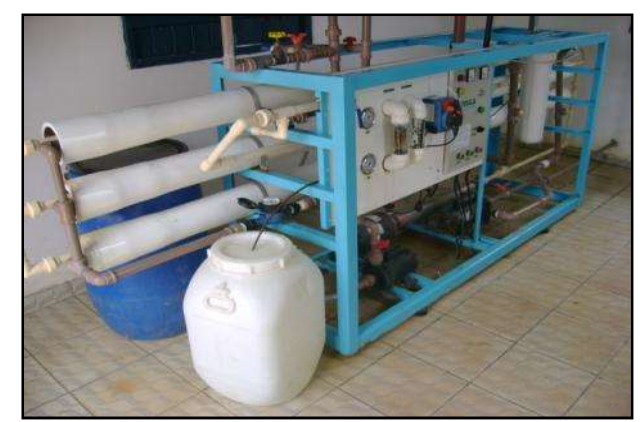

Figura 3: Dessalinizador da comunidade Uruçu.

\section{Características do Sistema de Dessalinização}

O dessalinizador é o equipamento responsável para realização do processo de dessalinização da água salobra do poço. A água do poço é a principal fonte hídrica de alimentação do dessalinizador para produção de água potável e suas características físicoquímicas estão relacionadas com a região onde o poço foi perfurado. $O$ dessalinizador desenvolvido no âmbito do LABDES possui Três vasos de alta pressão de fibra de vidro com três elementos de membranas, de Osmose inversa do tipo BW30-4040, em cada vaso. Bombona para auxiliar na limpeza química; Quatros manômetros; Dois rotâmetros; Bomba de alta pressão, Bomba auxiliar, Bomba de retrolavagem, é composto também por um poço tubular, bomba do poço, reservatório de alimentação (água bruta), abrigo de alvenaria, dessalinizador, reservatório para o permeado (água doce), reservatório para o concentrado, chafariz e tanques para contenção do concentrado.

O abrigo é o local onde o dessalinizador se encontra instalado, o qual sempre deve ser mantido limpo e em bom estado de conservação. Próximo ao abrigo se encontra os reservatórios de alimentação, do permeado e do concentrado. A distribuição da água para a comunidade é realizada no chafariz instalado próximo ao abrigo do dessalinizador. Na comunidade em estudo parte do rejeito é utilizado de forma sustentável na produção de cultivares hidropônicos, criação de peixes e evaporação. 


\section{RESULTADOS}

\section{Análises Físico-Químicas}

As análises físico-químicas realizadas serviram para monitorar a qualidade das correntes geradas pelo sistema de dessalinização. Na Tabela 1 é possível comparar os valores máximos permissíveis com os valores médios resultantes do monitoramento físico-químico de acordo com a Portaria 2914/11 MS.

Tabela 1: Ensaios físico-químicos analisados no sistema.

\begin{tabular}{lllll}
\hline Parâmetros & Permeado & Poço & Rejeito & ${ }^{*}$ VMP \\
\hline pH & 6,5 & 7,4 & 7,8 & $\mathbf{6 , 0 - 9 , 5}$ \\
Cor, (mg Pt-Co/L) & 0,0 & 10,0 & 10,0 & $\mathbf{1 5 , 0}$ \\
Turbidez, uT & 0,2 & 0,3 & 0,9 & $\mathbf{5 , 0}$ \\
Ferro, mg/L & 0,0 & 0,06 & 0,1 & $\mathbf{0 , 2}$ \\
\hline
\end{tabular}

*Valor Máximo Permitido pelo Ministério da Saúde.

$\mathrm{O}$ pH é um dos parâmetros mais importantes na determinação da maioria das espécies químicas de interesse tanto na análise do permeado quanto do poço e rejeito. Os resultados obtidos de acordo com a Tabela 1 estão dentro dos valores permissíveis, não apresentando problemas a saúde dos beneficiados pela água dessalinizada. Valores elevados de $\mathrm{pH}$ na água de alimentação podem indicar um potencial de precipitação de sais de carbonato de cálcio nas superfícies das membranas (SILVA, 2009). A existência na água de partículas coloidais ou em suspensão determina o aparecimento da cor. Essas partículas provêm do contato da água com substâncias orgânicas em estado de decomposição, da existência de compostos de ferro e outras matérias dissolvidas, para o nosso estudo as concentrações de ferro denotaram a relação que o íon apresenta com a cor, nota-se na amostra do poço e do rejeito a cor 10,0 sendo estas, a que apresentou maiores quantidades de ferro em relação à amostra de água do permeado.

Entre os parâmetros da Tabela 2, também obtidos através das análises físico-químicas, ficaram acima dos valores ideais para consumo todas as amostras da água do poço e do rejeito, entretanto a água permeada que será consumida pelos moradores, encontra-se dentro dos padrões estabelecidos, indicando a eficiência do dessalinizador em relação a remoção de sais na água.

Tabela 2: Ensaios físico-químicos analisados no sistema.

\begin{tabular}{|c|c|c|c|c|}
\hline Parâmetros & Permeado & Poço & Rejeito & *VMP \\
\hline Amônia, mg/L & 0,0 & 1,79 & 2,60 & 1,50 \\
\hline Dureza Total, $\mathrm{mg} / \mathrm{L}\left(\mathrm{CaCO}_{3}\right)$ & 30,00 & 530,50 & 852,50 & 500,0 \\
\hline Sódio, $\mathrm{mg} / \mathrm{L}$ & 22,33 & 469,85 & 707,25 & 200,0 \\
\hline Cloretos, $\mathrm{mg} / \mathrm{L}$ & 31,24 & 614,26 & $1.089,14$ & 250,0 \\
\hline (STD) Sólidos Totais Dissolvidos, mg/L & 76,75 & $1.911,19$ & $2.941,15$ & $1.000,0$ \\
\hline
\end{tabular}

*Valor Máximo Permitido pelo Ministério da Saúde.

A amônia está presente naturalmente em amostras de águas subterrâneas, superficiais e residuárias como pode ser visto na Tabela 2 , a amônia presente na água do poço. A dureza Total 
na água do poço e do rejeito apresentaram valores elevados de 530,5 e 852,5 mg/L que podem causar problemas de incrustações nas tubulações em dessalinizadores que não têm suas manutenções periodicamente. Do ponto de vista para consumo humano, são admitidos valores relativamente altos, a despeito do sabor desagradável que referidos níveis podem suscitar, não chegando a tornar objetável o uso dessas águas, cujo consumo também não causa problemas fisiológicos. No Brasil, o valor máximo permissível de dureza total fixado pelo padrão de potabilidade, ora em vigor, é de $500 \mathrm{mg} / \mathrm{L}$ expresso em Carbonato de Cálcio.

Os íons sódio e cloreto são os principais íons inorgânicos presentes em águas em geral a exemplo da água do poço e do rejeito do sistema de dessalinização, segundo estudo feito por Selligoi (1999),o íon sódio é um constituinte em maior quantidade das rochas cristalinas ígneas, cerca de $28.000 \mathrm{mg} / \mathrm{Kg}$. Ocorre em plagioclásio, principalmente albita $\left(\mathrm{NaAlSi}_{2} \mathrm{O}_{3}\right)$ e é liberado durante o intemperismo destes silicatos. O sódio é geralmente presente nas águas como íons $\mathrm{Na}_{+}$, em soluções concentradas ocorrem $\mathrm{NaCO}_{3}, \mathrm{NaHCO}_{3}$ e as mais altas concentrações estão associadas com os íons $\mathrm{Cl}^{-}$. O SDT representa a concentração de todo o material dissolvido na água, seja ou não volátil (SANTOS, 2000). Os STD também servem para indicar se a água é doce (0-500 mg/L), salobra (500-1.500 mg/L) ou salina (> $1.500 \mathrm{mg} / \mathrm{L})$ (APHA, 1998). Assim sendo, por esta escala, os valores de STD encontrados no poço e no rejeito indicam uma característica salina.

\section{CONCLUSÕES}

Os resultados das análises físico-químicas foram indicadores importantes para verificar as irregularidades principalmente da qualidade de água permeada pelo dessalinizador, que apresentaram composição química dentro dos limites permitidos pela legislação brasileira. Os resultados das amostras da água do poço e do rejeito apresentaram características salinas, que contribuem para incrustação nas membranas, sendo necessária a observância destas análises para possíveis pré-tratamentos químicos e/ou físicos do sistema de dessalinização e decisões das realizações das limpezas químicas dos elementos de membranas. É necessário que ocorra a fidelidade entre a comunidade e os órgãos que implantaram o sistema na localidade, assim, contribuir para a melhoria de vida destes moradores gera novas atitudes e posteriormente novos conceitos para melhoria da qualidade de vida de pequenas comunidades isoladas que vivem na pobreza e escassez de água potável. A alternativa de abastecimento por tratamento com membranas, possibilitou na permanência dos moradores rurais em suas residências, evitando a prática de emigração em busca de qualidade de vida.

\section{REFERÊNCIAS}

ANADÃO, P.. Ciência e tecnologia de membranas. São Paulo: Artliber, 2010. 
APHA, AWWA, WPCF. Standard Methods for the Examination of Water and Wastewater. 20 ed. Washington: American Public Health Association/American Water Works Association/Water Environment Federation, 1998.

BRASIL. Portaria MS n. 2914 de 12 de dezembro de 2011. Dispõe sobre os procedimentos de controle e de vigilância da qualidade da água para consumo humano e seu padrão de potabilidade. Brasília, 12 Dez 2011.

CELLIGOI, A.. Considerações sobre análises químicas de águas subterrâneas. Revista Geografia, Londrina, v.8, n.1, p.91-97, 1999.

HABERT, A. C.; BORGES, C. P.; NÓBREGA, R.. Processos de separação com membranas. Rio de Janeiro: COPPE, 2006.

IBGE. Instituto Brasileiro De Geografia e Estatística. Censo demográfico 2010. Brasília, 2010.

LIRA, W. S.. Recursos Naturais: uma abordagem multidisciplinar. João Pessoa: Realize, 2012.

QUEIROZ, F. R. M.; SILVA, R. F.; BEZERRA, J. U. L.; GUIMARÃES, B. S.; FERNANDES, J. T. N.; FRANÇA, K. B.. Avaliação e comparação do desempenho de um sistema de membranas de micro/nano filtração com sistema de osmose inversa para diferentes níveis de concentração de sais de águas salobras da comunidade de Uruçu em São João do Cariri (PB). Revista de Biologia e Farmácia, v.09, p.01-12, 2013.

SANTOS, A. C.. Noções de Hidroquímica: conceitos e aplicação. 2 ed. Fortaleza: CPRM e LABHID, 2000.

SILVA, K. S.; MONTEIRO, G. S.; SILVA, J. N.; FERREIRA, W. B.; FRANÇA, K. B.. Estudo do índice de densidade de sedimentos em águas oriundas de poços tubulares aplicadas a sistemas de dessalinização via osmose inversa. Enciclopédia Biosfera, Goiânia, v.5, n.8, 2009.

SILVEIRA, M. C.; FRANÇA, K. B.. Avaliação do desempenho de um sistema de dessalinização via osmose inversa para águas salobras. IN: CONGRESSO BRASILEIRO DE ÁGUAS SUBTERRÂNEAS. 10. Anais. São Paulo: USP, 2009.

SOUZA, L. F.. Dessalinização como fonte alternativa de água potável. Revista Norte Científico, Boa vista, v.1, n.1, 2006.

VON, S. M.. Introdução à qualidade das águas e ao tratamento de esgotos. 3 ed. Belo Horizonte: UFMG, 2005. 